\title{
EJSBS
}

The European Journal of Social \&

Behavioural Science

ISSN: 2301.2218 (ONLINE)
OPENACCESS

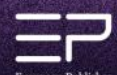

The European Journal of Social and Behavioural Sciences

EJSBS Volume 31, Issue 1 (eISSN: 2301-2218)

\section{THE ONGOING DISCUSSION ABOUT CADAVERIC DISSECTION IN MEDICAL EDUCATION: A PROPOSED INTEGRATED APPROACH}

\author{
Gail E. Elliott ${ }^{\mathrm{a} *(D)}$ \\ ${ }^{a}$ Department of Neuroscience and Cell Biology, Robert Wood Johnson Medical School, Rutgers University, New Jersey, USA
}

\begin{abstract}
Over the last decade, cadaveric dissection has been the focus of debate, regarding its value within the medical curriculum. Those against dissection cite, among other reasons, that dissection is overly time consuming and does not fit into the favoured team-based, case-based, or problem-based learning models. Further, alternative methods of learning anatomy (e.g., living anatomy, technology) have been incorporated into the lab as alternative for dissection. Newer medical schools are choosing not to include dissection at all, in favour of introducing clinical skills much earlier. Current literature shows dissection is still very popular and preferred among surgeons as a training tool, while students acknowledge that it is important for their learning. Alternative methodologies have also been reportedly popular with students and additional value lies in their incorporation of clinical skills (e.g., patient interviews). Therefore, a compromise has been reached with the proposal of the Integrated Dissection and Clinical Skills (IDCS) approach. This method of teaching anatomy would incorporate various techniques in a manner that puts student learning first. It is intended as a middle ground that will maximise learning by fitting dissection into the modern curricula designs in a more dynamic and engaging manner.
\end{abstract}

Keywords: Medical education, cadaveric dissection, anatomy in medicine, gross anatomy education

(C) 2022 Published by European Publisher. www.EuropeanPublisher.com

${ }^{*}$ Corresponding author.

E-mail address: ge111@rwjms.rutgers.edu

doi: $10.15405 /$ ejsbs.308 
https://doi.org/10.15405/ejsbs.308

eISSN: 2301-2218 / Corresponding Author: Gail E. Elliott

Selection \& Peer-review under responsibility of the Editors

\section{Introduction}

Opinion is strongly divided among medical educators regarding whether Cadaveric Dissection (CD) or alternative approaches are better for teaching anatomy. Numerous factors are responsible for different approaches to teaching gross anatomy in medical education. Yet, few considerations have been made for a middle ground option with a blending of available techniques for medical schools. Many publications have been used to discuss the costs and benefits of dissection in comparison to alternative techniques, such as computer-based models (Benly, 2014; Kurt et al., 2013; McMenamin et al., 2018; Memon, 2018; Sadler et al., 2018). Medical educators are also publishing research on different approaches to anatomy teaching, including plastic models, videos, computer software, medical imaging, plastinated specimens, and prosections indicating a general wish to find alternatives to CD (Azer \& Azer, 2016; Howe et al., 2004; Kurt et al., 2013). This varied approach to teaching anatomy is becoming more common and has resulted in disparities in anatomical knowledge of medical graduates between different universities. Further research shows that the debate between cadavers vs. alternative teaching methods has continued to grow over the last decade.

The literature for CD highlights several areas of that produce positive outcomes for medical students and ultimately physicians in the field. These areas include (1) knowledge retention, (2) active learning, (3) understanding anatomical relations, (4) teaching respect for another person's body, (5) development of the first physician-patient relationship, (6) teamwork, and (7) learning to deal with death professionally (Dissabandara et al., 2015; Habicht et al., 2018; Rani et al., 2016; Mutalik \& Belsare, 2016). The literature against $\mathrm{CD}$ is adamant that live dissection can effectively be replaced with living anatomy (e.g., body painting, palpating, and surface anatomy), technology including virtual dissection tables (e.g., Anatomage and Sectra) or computer applications like Complete Anatomy, medical imaging, and plastinations or prosections. The arguments for these methods include making the sessions more realistic as medical imaging and palpation are incredibly important to physicians, while plastinations and prosections are more time effective and students can spend that time learning the pathways of the structures, rather than looking for them as they would in a live dissection class (Asaid \& Nasir 2015; Donelly et al., 2009; Mutalik \& Belsare, 2016; Patten 2007; Sectra 2019). The current landscape of anatomy teaching is one of mixed opinions about the best way of teaching anatomy and has focused on replacing cadaver. This paper will explain the current issues surrounding the anatomy teaching landscape. Second, the pros and cons of the various techniques of anatomy learning in medical education will be explored. Third, an integrated model of anatomy teaching techniques will be proposed that take advantage of the benefits of each learning method.

\section{The Current State of Dissection and Gross Anatomy in Medical Education}

Dedicated gross anatomy teaching hours have been in steep decline in medical education over the last 30 years in favor of clinical skills (Tibrewal, 2006). Studies from Nigeria, the U.K., the U.S.A., Australia, and New Zealand show this is a global phenomenon and is attributable to several causes (Craig et al., 2010; Papa \& Vaccarezza, 2013; Tibrewal, 2006; Turney, 2007). The greatest concern for this knowledge decline has come from experienced medical professionals who have noticed a serious deterioration in the anatomical knowledge of medical graduates over the last decade. For example, in 1999, a survey of surgical program directors in the U.K., showed that their surgical trainees were seriously 
https://doi.org/10.15405/ejsbs.308

eISSN: 2301-2218 / Corresponding Author: Gail E. Elliott

Selection \& Peer-review under responsibility of the Editors

deficient (24\%), or in need of a revision course in anatomy (67\%), and more than $50 \%$ stated that anatomy knowledge had dropped drastically in the last decade (Cottam, 1999). Further, Dr. Oliver Beahrs, a surgeon of international standing at the Mayo Clinic, has raised additional concerns by suggesting that trainee surgeons have so little anatomical knowledge, they may harm their patients (Green, 1998). These findings and growing concerns may be linked to the reduction of gross anatomy from the curriculum or its substitution with other techniques. The causes for these changes and the potential consequences described above will be discussed here in considering their potential impact on the anatomical knowledge of medical graduates.

\subsection{Section headings}

The first cause anatomical dissection decline is discontent towards traditional teaching methods. This dissatisfaction is linked to perceptions that medical education can always be taught in new and novel ways to improve the quality of junior doctors and their ability to diagnose and treat patients. There are also discussions amongst medical educators as to whether a transition towards problem-based (PBL), case-based $(\mathrm{CBL})$, or team-based (TBL) curricula are better approaches to teaching medical students than didactic lectures and CD (Memon, 2018; Turney, 2007). In schools where PBL/CBL/TBL formats are used, studentfaculty interfacing hours are significantly reduced in favor of self-directed study (Turney, 2007). This condensed student-facing time means that time-consuming activities in the curriculum, such as CD, have been replaced in favor of more self-study opportunities. However, changes to anatomy teaching have not historically been successful. In the U.K., the reduction of dissection time at many schools around the country has led to growing concerns about the poor anatomical knowledge of medical school graduates and this was linked to a steep rise in the numbers of avoidable deaths and incidents of medical malpractice related to poor anatomical knowledge (Cahill \& Leonard, 1997; Ellis, 2002). The mixed perceptions of the value of $\mathrm{CD}$ have resulted in this prolonged argument of for or against dissection. Many educators continue to believe in the importance of dissection, although it is constantly under review in the curriculum as others try to replace it.

Over the last two years, due to emergency remote learning in many educational contexts there are further complications for those who believe in the importance of dissection for student learning. The institutional fallout from COVID-19 and restrictions associated with the need for social distancing may also play an important part in the future of $\mathrm{CD}$ at medical schools. This is because over the last year, medical schools have had to be inventive in teaching anatomy without using the dissection lab for a variety of reasons: proximity around the table, and no guarantee that the cadavers were completely safe until testing was available for them. As a result, many schools now recognize that anatomy can be taught with alternative methods and may be reconsidering the future of their CD programs.

\subsection{Ever-tightening Institutional Budgets and Human Tissue Acts}

Additional factors leading to the disappearance of $\mathrm{CD}$ from the medical curriculum include the substantial costs of storing cadavers, extra personnel needed to run the laboratory, and the implementation of local laws surrounding handling, use, and disposal of human tissue (Craig et al., 2010; Human Tissue (Scotland) Act 2006; Habicht et al., 2018). This is especially true for the U.K. and Europe, where human tissue laws are strict and highly regulated. There is also a growing difficulty for medical schools to secure 
the numbers of cadavers needed for each new student class. These challenges are linked to growing concerns for the sourcing of cadavers, including unclaimed bodies and bodies of executed prisoners in some parts of the world being used for medical education. Habicht et al. (2018) surveyed 71 countries, reporting bodies were sourced from donation programs in 22 countries and mostly unclaimed bodies in the remaining 49 countries. These findings prompted calls to implement standards regulating cadaver sourcing (IFAA, 2012; Riederer \& Bueno-López, 2014).

Religious and cultural beliefs, as well as an unprecedented development of new medical schools also contribute to this cadaver shortage. As a result, many universities have higher than ideal cadaver to student ratios (Mutalik \& Belsare, 2016). Mutalik and Belsare (2016) suggest an 'ideal' ratio of ten students to each cadaver, identifying that most medical schools in India typically experience ratios of 20:1 or higher. The result is that students do not get to dissect often and crowding around the dissection table prevents many students from seeing structures, and consequently, become disinterested and/or disengaged. Clearly, the ratio of students to cadavers is a critical element to the CD experience and student learning. As student numbers increase and cadaver numbers fall, there is a greater risk of student disengagement and falling popularity of dissection that has no real link to the dissection experience itself.

\subsection{A Lack of Global Standards for Medical School Anatomy Knowledge}

The greatest reason for the disparity of anatomical knowledge amongst graduating medical students is that there are no current nationwide or global standards for the amount of gross anatomy taught within a medical curriculum. This leaves institutions to unilaterally determine how much gross anatomy to incorporate into their curriculum (Craig et al., 2010; Papa \& Vaccarezza, 2013). This absence of standards for anatomy knowledge between medical degrees may be attributed to an absence of anatomy committees and professional bodies of medical educators regulating levels of gross anatomy taught. Because of these disparities in anatomy training, and the perceived lower value of anatomy compared to other subjects in medicine, students graduate with considerable variation in levels of gross anatomy knowledge, which may seriously impact on their professional performance. The perception is that gross anatomy is less important than other subjects in the medical curriculum. This is because gross anatomy has not changed since the initial documenting of gross structures in the human body. Other subjects such as biochemistry and physiology have continued to advance with new discoveries. In addition, there has been a big push to start clinical skills training much earlier in the curriculum, and this has meant that the subjects typically taught in the first and second years of medical schools now have less and less time as they compete with subjects usually left to third and fourth years. Despite these changes, gross anatomy remains the cornerstone of good medical practice.

The current landscape for gross anatomy in medical education is inconsistent and brought about by shifting attitudes towards dissection and how medical students should be trained. Unfortunately, very little is being done to recognize the importance of anatomy training. This is a significant issue because the impact of less training is only seen in hospitals and in regional statistics for medical malpractice, but not directly in real time by institutions. It is obvious that $\mathrm{CD}$ does have its place, otherwise, it would have been systematically removed from medical education. However, a review of the value of dissection along with other techniques that are implemented is worthwhile when considering a more holistic approach to teaching anatomy in the lab and maximizing the use of the time spent there. Time in the gross dissection lab is only 
a waste in the curriculum when not used effectively. Therefore, consideration of how this time can be used must be established. To maximize the teaching and learning context of anatomy must first highlight the benefits of available methods, before proposing an integrated approach for the dissection laboratory. This approach is proposed because gross anatomy dissection is still valued by many educators, students, and medical professionals, although much has been done to replace it with alternative methods of learning

\section{A Review of Current Teaching Methods}

In this section, $\mathrm{CD}$ and the alternative methods used will be reviewed considering current research to highlight the benefits and build awareness of some of the costs of these different techniques. The methods included are CD, living anatomy (e.g., body painting, palpation, and surface anatomy), technology, such as the virtual dissection tables (e.g., Anatomage, Sectra), and computer applications (e.g., Complete Anatomy and Virtual Human Dissector), prosections and plastinations, and medical imaging.

\subsection{Cadaveric Dissection}

Cadaveric dissection is the most popular method of learning anatomy among students and physicians (Asaid \& Nasir, 2015; Collett et al., 2009; Ganguly \& Chan, 2008; Habicht et al., 2018; Romero-Reveron, 2017). As previously mentioned, the research literature shows that $C D$ is popular because it helps students with knowledge retention, makes learning engaging, aids in conceptualization of anatomical relationships, teaches respect for another person's body, introduces the first physician-patient relationship, and helps students learn to deal with death professionally (Asaid \& Nasir, 2015; Collett et al., 2009; Dissabandara et al., 2015; Mutalik \& Belsare, 2016; Rani et al., 2016; Selcuk et al., 2019).

Disadvantages of CD include dissociation in students, discomfort being confronted with death, high student to cadaver ratios (e.g., 20:1); and a lack of time in the curriculum for CD (Collett et al., 2009; Inuwa et al., 2012; Khan et al., 2014; Kurt et al., 2013; Purvi et al., 2015). Despite the negative findings, most students reported CD was indispensable to their learning. Even those who preferred other forms of learning over dissection felt that missing out on dissection would be disadvantageous to their understanding of the human body (Dissabandara et al., 2015; Kemeir, 2012; Mutalik \& Belsare, 2016; Rani et al., 2016; Tseng \& Lin, 2016). Professional opinions mirror those of students, with dissection considered the best way to learn anatomy. For example, $88 \%$ of 65 Venezuelan surgeons surveyed agreed dissection is optimal for learning gross anatomy (Romero-Reveron, 2017).

\subsection{Living Anatomy}

Living anatomy (e.g., body painting, palpation, and surface anatomy) is used with growing frequency in medical education. This positive evolution has resulted from a perception by medical educators that activities, such as palpation, mimic common physician practices (Collett et al., 2009; Ganguly \& Chan, 2008; Green \& Dayal, 2018; Mutalik \& Belsare, 2016). For example, palpation allows students to better understand the patient experience as they act as 'life models' for their peers and reduces anxiety over having to perform basic exams (Ganguly \& Chan, 2008; McLachlan \& Regan de Bere, 2004; Wearn \& Vnuk, 2005). There are also advantages for body painting and palpation including the understanding of surface relations, the value of kinesthetic activities for learning, and sensory input for those acting as canvases, while improving communication skills and professional examination techniques, 
https://doi.org/10.15405/ejsbs.308

eISSN: 2301-2218 / Corresponding Author: Gail E. Elliott

Selection \& Peer-review under responsibility of the Editors

essential to physicians (Asaid \& Nasir, 2015; Finn, 2018; Finn \& McLachlan, 2010; Patten, 2007). It is also cost-effective due to the low costs of the paint and brushes.

Disadvantages of these techniques include limitations to surface areas, while body painting specifically, is useful for larger structures, such as muscles or sensory dermatomes (Bowsher, 1976; Op Den Akker et al., 2002). There are also social limitations as students may refuse to participate due to religious beliefs, social discomfort, and the value for learning retention is unknown (Jarivapong et al., 2016). Therefore, planning to incorporate same-sex groups, painting on old clothes, and allowing students to choose their groups is necessary and time-consuming (Op Den Akker et al., 2002). Despite these limitations, living anatomy is popular, with $89.8 \%$ of 304 students at MIMER medical college, India, requesting more living anatomy in their classes (Mutalik \& Belsare, 2016).

\subsection{Technology}

Technology is considered one of the best alternatives to CD (Anand \& Singel, 2017; Donelly et al., 2009; Dissabandara et al., 2015; Rehman et al., 2012; Zurada et al., 2011). This favor for technology as a replacement is because it is clean compared to dissection and is thought to offer many of the advantages of dissection, for example, being able to view anatomical relations or arterial pathways. Removal of dissection over the last decade has occurred in parallel with the development of sophisticated virtual dissection tables, for example, Sectra and Anatomage, and computer applications, including Complete Anatomy and the Visible Human Dissector (Anatomage, 2019; Complete Anatomy Application, 2019; Donelly et al., 2009; Sectra, 2019; Toltech, 2019). Research shows these computer applications have been well received. For example, Donnelly et al. (2009) report the Visible Human Dissector is extremely useful for understanding cross-sectional anatomy. There is clearly an advantage to having technology to teach gross anatomy (Anand \& Singel, 2017; Bharati et al., 2018; Fyfe et al., 2018). For example, Bharati et al. (2018) report that 90\% of 150 students agreed that the Anatomage table should be used in conjunction with dissection rather than instead of it.

The limitations of technology are linked to low numbers of virtual models and a lack of exposure to natural human variation in the presentation of different anatomical structures (Anatomage, 2019; Complete Anatomy Application, 2019; Donelly et al., 2009; Sectra, 2019; Toltech, 2019). For example, Complete Anatomy, the Virtual Human Dissector, and Sectra contain single male models, while females are partially represented in Complete Anatomy. These programs may also require powerful computers to run them. For example, the Visible Human Dissector's male model requires $15 \mathrm{gb}$ of space and a powerful computer to render the images effectively (NIH, 2019; Toltech, 2019).

There is still much debate as to whether the pros of the current technology available would be sufficient to lead to a complete replacement of cadaveric dissection. A strong push over recent years has occurred with the general idea that more modern approaches to teaching must involve technology and that the smells and discomfort of working with cadavers is an old school approach. Yet, there is still much progress to be made with the technology as discussed above, with very few models available in some of the virtual tables and computer applications and a strong focus on male models in each of these. Further, there is very little that shows up the natural variation, and technology does shield students from adjusting 
https://doi.org/10.15405/ejsbs.308

eISSN: 2301-2218 / Corresponding Author: Gail E. Elliott

Selection \& Peer-review under responsibility of the Editors

to the more uncomfortable aspects of dealing with people that they would only then be exposed to during patient interactions in their clinical years.

\subsection{Prosections and Plastinations}

Prosections and plastinations are extremely popular for learning anatomy (Kemeir, 2012). Benefits include better information retention and improve understanding of spatial and radiological anatomy (Nnodim, 1990; Romero-Reveron, 2017; Samarakoon et al., 2016; Williams et al., 2019). These specimens for teaching are most beneficial, perhaps because they are professionally dissected, reducing student study time, and providing clear specimens for students to study.

Disadvantages of prosections and plastination are minor but they do not have the same impact as dissection for the students (Topp, 2004). For example, prosections and plastination do not help students to cope with death professionally, respect another human's body, or to teach the necessary detachment from the task at hand. Further, finding a structure through dissection engages students to get their bearings by looking at context and other reference points but that is not an option here. Clearly compared with CD, prosections and plastinations do have advantages for reducing time in lab and allow inexperienced students to view clear anatomical specimens. However, there are aspects of dissection, such as the development of manual dexterity, that are missed by observing and learning may not be as engaging for students.

\subsection{Medical Imaging}

Medical imaging is understandably emphasized in medical education due to its clinical relevance (Ertl-Wagner et al., 2016; Jack \& Burbridge, 2012; Sadler et al., 2018; Swamy \& Searle, 2012). Therefore, the advantages of introducing the imaging into sessions is linked to the greater ability of physicians to read clinical reports in their careers. Interestingly, while medical imaging is important, the amount of time dedicated to it is highly variable. For example, Jack and Burbridge (2012) surveyed 14 medical schools in Canada, reporting $40 \%$ of schools used radiology during $20 \%$ of their anatomy teaching course. There are also favored techniques, with radiology and CT being incorporated to a much greater extent than MRI and ultrasound with continued calls for greater integration of CTs (Hassan et al., 2016; Jack \& Burbridge, 2012). The result is noticeable disparities in ability to read radiographs and may provide challenges for graduating medical students during their initial years of clinical practice. There are no agreed upon disadvantages for teaching medical imaging within the curriculum. The disparities in emphasis on teaching imaging is the only real struggle and there needs to be a greater consistency across medical schools.

\subsection{Section Summary}

Medical education currently has several resources available for teaching anatomy. With the quick review of each technique, there are certainly advantages to using each of the methods available, although the body of research does suggest that these methods should be used in conjunction with each other, rather than in isolation. It is clear that the teaching of anatomy requires an integrated approach to deal with this multifactorial issue. As a result, careful planning, and co-ordination among teaching faculty as curriculums are altered does provide the opportunity to capitalize on the benefits a wide variety of techniques (e.g., CD, living anatomy, technology, and plastinations) for students. An integrated approach is proposed below, laid out as potential options for medical schools to implement. This would provide the most comprehensive 
https://doi.org/10.15405/ejsbs.308

eISSN: 2301-2218 / Corresponding Author: Gail E. Elliott

Selection \& Peer-review under responsibility of the Editors

teaching experiences for students that would maximize the benefits of all available anatomy teaching methods. This would also work in concert with the direction that most medical curriculum in most medical schools are going, emphasizing TBL/PBL/CBL that is currently favored as the best approach for teaching medical students.

\section{The Proposed Integration Approach}

There are two major issues affecting CD in modern medical curriculums. First, it is widely held that $\mathrm{CD}$ is overly time-consuming because $\mathrm{TBL} / \mathrm{PBL} / \mathrm{CBL}$ have been allocated a greater importance in the medical student experience. Thereby, limiting the amount of CD contact time for students. Second, CD is perceived as a relatively passive learning experience for students who are not directly performing the physical dissection. Although previous strategies have been attempted to engage non-dissecting students into the active learning process through various role assignments (e.g., the reader, active questioning), these strategies have proven to be less than effective in keeping students engaged in the CD process. Despite these challenges for dissection in medical education, several avenues of specialization (e.g., surgical residencies) still require significant dissection time (Hassan et al., 2016).

In contrast to $\mathrm{CD}$, there are several beneficial modalities_that have been introduced into medical education that mimics the skills physician uses in everyday practice (e.g., reading medical images). Medical imaging is an important example because it is an extremely useful diagnostic tool, taught with varying emphasis from school to school (Jack \& Burbridge, 2012). Based on the literature student surveys show that the best approach to learning anatomy included CD in conjunction with new and alternative modalities (Dissabandara et al., 2015; Rehman et al., 2012; Romero-Reveron, 2017). For example, Bharati et al. (2018) report that $90 \%$ of 150 students surveyed wanted the Anatomage table to be used in conjunction with CD. Supporting research shows that students do appreciate CD classroom experiences combined with alternative methodologies to supplement learning (Dissabandara et al., 2015; Rehman et al., 2012; Zurada et al., 2011). Therefore, an integrated approach, that incorporates a variety of anatomy learning techniques while emphasizing newer approaches that include TBL/PBL/CBL curriculum designs, offers a more dynamic experience learning anatomy in medical education. This approach would also need to build on the emphasis of diagnostic abilities that the medical curriculum is slowly developing through constant integration of subject materials through the teaching of organ-based systems.

Current trends in medical curricula design call for greater integration of subjects, the earlier introduction of clinical skills and a greater focus on diagnostic reasoning. There is also the ongoing argument for and against dissection within the curriculum that has led to the development of several modalities for teaching gross anatomy. The timing is perfect for a middle ground approach that takes into consideration all the different aspects without the removal of dissection. Rather, integration of dissection and other modalities of learning (e.g., living anatomy, medical imaging, and technology, can be carefully done to create an optimal learning experience for medical students in the first and second years, while complimenting the new curriculum. This approach, the Integrated Dissection and Clinical Skills Approach (IDCS) is described below in detail. 


\subsection{The Dissection Component}

Within this integrated approach, $\mathrm{CD}$ is positioned to sit within the organ-based systems medical curriculum in a similar manner to its current position as a foundational element. In terms of physical space requirements, time requirements and student to cadaver ratios minimal changes would occur. Traditionally, dissection classes lean on the "see one, do one, teach one" philosophy, and this may be particularly important in instances with incredibly high student numbers, preventing some students from being able to see the step-by-step dissection. This formula is used because there is evidence to show that it is simple but effective (Kotsis \& Chung, 2013). Dissection will also help students to learn the anatomy quickly and effectively through vicarious learning from other students (Roberts, 2010). To take advantage of vicarious learning in this model, students would sign up to dissect in each lab (e.g., two dissectors). These two students would observe prosections first with a demonstration by faculty, before beginning their own dissection. The remaining students for that table would go to complete the non-dissection components of the lab, while the dissection commenced.

Considerations for keeping the dissection in this model are all described benefits of dissection, with emphasis on dexterity development with tools. For example, familiarity with scalpels and learning to blunt dissect with scissors takes time to develop, hence a preference for dissection by surgical residencies (Romero-Reveron, 2017). The result is that this component of the lab remains developed and emphasized due to its importance in student learning, while the non-dissection component for those students who are not dissecting requires more development.

\subsection{The Non-Dissection Component}

The non-dissection component makes use of overlooked opportunities to engage students through active learning. This component may be tailored in various ways, depending on institutional budgets, faculty availability, and space constraints. For example, some of the methodologies would be most useful, if each student had an iPad or tablet, which may not be within the school's budget. This part of the lab is devised for students who are not dissecting to enable them to engage with the material in different ways that take advantage of the benefits of the techniques. For example, screens with the virtual human dissector or Anatomage could be used to review anatomy. For medical imaging, some departments have ultrasound machines in lab for students to practice, getting them used to using these machines and carrying out patient exams. If this is impossible, then at the very least, images could be made available for students to review, making the amount of medical imaging more consistent throughout the curriculum. Finally, palpation stations, and body painting stations could also be set up as well to tie in the material in a way that engages students to reason. For example, case studies linked to material covered, could be created that involve students going to each of the stations to look at different materials and then attempt to use their deductive reasoning skills. These students would then go back to the dissection table and receive a lesson from their peers about the progress made in the dissection. Dissectors then transfer their roles to the non-dissectors, so they may experience the additional modalities of learning. An example of what this could look like is provided below. These modalities would be introduced into the program because they help students with information retention (e.g., body painting's kinesthetic value) (Asaid \& Nasir, 2015). 


\subsection{Applying the Integrated Approach: The Heart Dissection Lab Example}

The example used here is the internal and external heart dissection lab. In this example, students who are not dissecting would be given a case study that sets up a scenario for them with a vignette. The students would then work through a series of stations where they would work to review material and reach a diagnosis for the patient. The following example is for a patient that has experienced a myocardial infarction with twenty minutes allotted to students for each of the following stations.

\subsubsection{The Living Anatomy Station}

For example, if the scenario is a myocardial infarction (MI), students would attend a workstation to draw the locations of auscultation points for heart valves onto a peer. They may also identify the dermatome of the T1 intercostobrachial nerve, responsible for the pain sensation in the left upper limb. Again, the benefits of this station were outlined in Section 3.2 where living anatomy exercises (e.g., body painting, and palpation) help to reduce student anxiety over performing physical exams and familiarize them with understanding surface relations. Those acting as canvases are also engaged in the learning process through sensory stimuli (Ganguly \& Chan, 2008; McLachlan \& Regan de Bere, 2004; Wearn \& Vnuk, 2005).

\subsubsection{The Medical Imaging Station}

At this station, students review medical images from several modalities (e.g., MRI, ultrasounds, radiographs, and $\mathrm{CT}$ scans) to become familiar with different views of the internal anatomy. Numbering of anatomical structures ensure students identify relevant structures, preventing them from being overwhelmed. It is also common for medical schools to own ultrasound machines, and if available, these would be incorporated at this station for students to perform ultrasounds on themselves or standardized patients (Fakoya, 2013; Patten, 2015; Russell et al., 2021). Benefits of students performing ultrasound early in their training helps them to become familiar with performing patient interviews and learning to use an ultrasound machine, both necessary clinical skills (Jack \& Burbridge, 2012; Hassan et al., 2016). The greatest importance of introducing this station into the anatomy lab is to attempt to increase the amount of medical imaging taught and to reach a level of consistency between schools and because being able to read medical images is an incredibly important clinical skill (Jack \& Burbridge, 2012).

\subsubsection{The Technology Station}

At this station, students review anatomical structures in situ using the virtual dissection tables, or touch screen computers running applications (e.g., Complete Anatomy and the Virtual Human Dissector). For example, the Complete Anatomy application would be used to review the coronary circulation, relating to the myocardial infarction. Students could be asked to identify the artery that is most likely to be blocked, based on the position of the MI. Further, the Virtual Human Dissector could be used to review the crosssectional anatomy to confirm the student's findings from the medical imaging station. Complete Anatomy may also be used to test students' knowledge through quizzes with drop down answers that facilitate the learning and engagement in real time, all of which would be advantageous in this lab time. 


\subsubsection{The Clinical Case Study Station}

This station is faculty-led and would involve tying the entire case study together for the students. One example was discussed here (MI), but students could consecutively run through multiple case studies, with different colours used to highlight the important aspects for each case study. They could then come together to discuss the case studies with a member of faculty at the final station, before returning to their dissection table. Alternatively, this station may be used to introduce additional case studies from lectures to engage students in consolidation of their understanding about clinical anatomy. For example, videos, images, medical imaging, histology, and embryology, may be incorporated to foster a higher level of engagement with the material and an opportunity to interact with faculty. Finally, students will diagnose their patient and return to their dissection group. Here they will receive a brief tutorial of the progress made in dissection and will then takeover so their peers can complete the case study experience.

\subsubsection{Additional Considerations}

This proposed approach presents an opportunity to develop dedicated dissection time in the modern medical curriculum, through appropriate integration. This proposed learning environment incorporates a multi-modal approach to learning anatomy, while focusing on important clinical components (e.g., medical imaging, palpation). The benefits of this approach to studying anatomy incorporate all positive aspects of these different learning methods (e.g., vicarious learning, kinesthetic learning), while recognizing concerns in the clinical community about the importance of anatomy dissection to manual dexterity, learning to cope with death, and preserving the first physician-patient relationship (Asaid \& Nasir, 2015; Mutalik \& Belsare, 2016; Collett et al., 2009; Dissabandara et al., 2015; Mutalik \& Rani et al., 2016). There are additional stations that may be incorporated into relevant labs (e.g., osteology, embryology, or histology). The result is a uniquely developed lab for each anatomical focus, creating flexibility in the teaching and fostering engagement of students.

This approach addresses concerns regarding dedicated dissection time. For example, students in the example created would see prosections, dissect, interpret medical images, review referred pain as a diagnostic tool (dermatomes), and perform palpation exercises to identify heart valve locations on a peer using their patient examination skills. The students would also review cardiovascular supply of the heart and complete a case study by diagnosing the patient. The result is a learning experience worth investing the effort and time to engage students.

The limitations for this proposed approach are expected: (1) time to develop the case studies; (2) larger numbers of faculty members involved; (3) faculty needing to learn to use ultrasound machines; (4) lengthy set-up times for each lab; (5) time to develop and create prosections; and (6) the cost of buying and installing the technology. Additional challenges include space required for these extra stations and may involve incorporating rooms near the dissection lab. There are also additional considerations about the living anatomy component as discussed above that would take careful planning to consider social aspects of the task (e.g., religious beliefs, and social discomfort) (Jarivapong et al., 2016). These issues are proportional to the level of engagement each university puts into this component of the learning experience. 
https://doi.org/10.15405/ejsbs.308

eISSN: 2301-2218 / Corresponding Author: Gail E. Elliott

Selection \& Peer-review under responsibility of the Editors

\section{Conclusion}

Cadaveric dissection is the cornerstone of medical education and has earned its place within the medical curriculum. Reduction in dissection time has been carried out in favor of incorporating clinical skills earlier in physician training at the expense of the quality of clinical practice. This is evidenced by the noticeable increase in anatomy-related instances of medical malpractice. In addition, the modern medical curricula favor team-based, problem-based, and case-based learning, which reduces faculty-student interfacing hours in favor of more self-directed study time. These changes have led CD hours to be cut or $\mathrm{CD}$ to be removed in favor of other modalities of teaching gross anatomy. There has also been much debate about the value of dissection and whether anatomy can be taught without it. These curricular changes, particularly relating to the removal or reduction of dissection have led to concerns among clinicians about the lack of anatomical knowledge, for example, in trainee surgeons (Green 1998; Romero-Reveron, 2017; Sing \& Tubbs, 2015). Over the last decade, strong arguments have been developed for and against dissection. Yet, there is a strong middle ground to give students an optimal educational experience. This proposed integration model (IDCS) is positioned to acknowledge the importance of dissection for many clinical specialties, while recognizing the value of different modalities for teaching gross anatomy and engaging medical students. Finally, this model provides an opportunity in the dissection lab to direct learning towards a diagnostic focus, a skill that needs to be developed from the beginning of formal medical training.

\section{Acknowledgements}

The author(s) declare that there is no conflict of interest.

\section{References}

Anand, M. K., \& Singel, T. C. (2017). A comparative study of learning with "Anatomage" virtual dissection table versus traditional dissection method in neuroanatomy. Indian Journal of Clinical Anatomy and Physiology, 4(2), 177-180. https://www.ipinnovative.com/journal-article-file/4138

Anatomage. (2019). World's First Virtual Dissection Table.https://www.anatomage.com/table/

Asaid, M. R., \& Nasir, N. (2015). Role of Living and Surface Anatomy in Current Trends of Medical Education. IJARIEE, 1(2), 2395-4396.

Azer, S. A., \& Azer, S. (2016). Anatomy Models and Impact on Learning: A Review of the Quality of the Literature. Health Professions Education, 2, 80-98. https://doi.org/10.1016/j.hpe.2016.05.002

Benly, P. (2014). Teaching Methodologies on Anatomy - A Review. J Pharm Sci Res, 6, 242-243.

Bharati, A. S., Kumari, S., \& Rani V. S. (2018). A Study on Student Perception of Virtual Dissection Table (Anatomage) at GSL Medical College, Rajahmundry. Academia Anatomica International, 4(2), 2831. https://doi.org/10.21276/aanat.2018.4.2.8

Bowsher, D. (1976). What should be taught in anatomy? Med Educ, 10, 132-134. https://doi.org/10.1111/j.1365-2923.1976.tb00546.x

Cahill, D. R., \& Leonard, R. J. (1997). The role of computers and dissection in teaching anatomy: a comment [editorial]. Clinical Anatomy, 10, 140-141. https://doi.org/10.1002/(SICI)10982353(1997)10:2<140::AID-CA13>3.0.CO;2-K

Collett, T., Kirvell, D., Nakorn, A., \& McLachlan, J. C. (2009). The role of living models in the teaching of surface anatomy: Some experiences from a UK Medical School. Medical Teacher, 31(3), e90e96. https://doi.org/10.1080/01421590802516731

Complete Anatomy Application. (2019). Your 3D anatomy companion from student to professional. https://3d4medical.com/press-category/complete-anatomy. 
Cottam, W. W. (1999). Adequacy of medical school gross anatomy education as perceived by certain postgraduate residency programs and anatomy course directors. Clinical Anatomy, 12, 55-65. https://doi.org/10.1002/(SICI)1098-2353(1999)12:1<55::AID-CA8>3.0.CO;2-O

Craig, S., Tait, N., Boers, D., \& McAndrew, D. (2010). Review of anatomy education in Australia and New Zealand Medical Schools. ANZ J Surg, 80, 212-216. https://doi.org/10.1111/j.14452197.2010.05241.x

Dissabandara, L., Nirthanan, S. N., Khoo, T. K., \& Tedman, R. (2015). Role of cadaveric dissections in modern medical curricula: a study on student perceptions. Anat Cell Biol, 48, 205-212. https://doi.org/10.5115/acb.2015.48.3.205

Donelly, L., Patten, D., White, P., \& Finn, G. (2009). Virtual human dissector as a learning tool for studying cross-sectional anatomy. Medical Teacher, 31(6), 533-555. https://doi.org/10.1080/01421590802512953

Ertl-Wagner, B., Barkhausen, J., Mahnken, A. H., Mentzel, H. J., Uder, M., Weidemann, J., \& Stumpp, P. (2016). White Paper: Radiology Curriculum for Under-graduate Medical Education in Germany. Academic Radiology, 188, 1017-1023. https://doi.org/10.1055/s-0042-116026

Fakoya, F. A. (2013). Integrating ultrasound technology into teaching gross anatomy: point of order! Med Educ Online, 18. https://doi.org/10.3402/meo.v18i0.20888

Fyfe, S., Fyfe G., Dye, D., \& Radley-Crabb, H. (2018). The Anatomage Table: Differences in student ratings between initial implementation and established use. Australia and New Zealand Association for Health Professionals, 19(2), 41- 52. https://fohpe.org/FoHPE/article/view/215/131

Ganguly, P. K., \& Chan, L. K. (2008). Living anatomy in the $21^{\text {st }}$ century: how far can we go? Southeast Asian Journal of Medical Education, 2(2), 52-57.

Green, H., \& Dayal, M. R. (2018). A Qualitative Assessment of Student Attitudes to the Use of Body Painting as a Learning Tool in First Year Human Anatomy: A Pilot Study. International Journal of Anatomy and Research, 6(2.1), 5134-5144. https://doi.org/10.16965/ijar.2018.140

Green, N. A. (1998). Anatomy training for surgeons - a personal viewpoint. Journal of the Royal College of Surgeons of Edinburgh, 43(1), 69-70.

Habicht, J. L., Kiessling, C., \& Winkelmann, A. (2018). Bodies for Anatomy Education in Medical Schools: An Overview of the Sources of Cadavers Worldwide. Academic Medicine, 93(9), 1293-1300. https://doi.org/10.1097/ACM.0000000000002227

Hassan, A., Barry, D. S., Gutierrez, H., Cryan, J. F., \& O'Keeffe, G. W. (2016). Cadaveric anatomy in the future of medical education: What is the surgeon's view? Anatomy Sciences Education, 9(2), 203208. https://doi.org/10.1002/ase. 1560

Howe, A., Campion, P., Searle, J., \& Smith, H. (2004). New Perspectives - approaches to medical education at four new UK medical schools. BMJ, 329, 327-331. https://doi.org/10.1136/bmj.329.7461.327

Human Tissue (Scotland) Act 2006.

International Federation of Associations of Anatomists (IFAA). (2012). Recommendations of good practice for the donation and study of human bodies and tissues for anatomical examination. Plexus: Newsletter of the IFAA, 4-5.

Inuwa, I. M., Taranikanti, V., Al-Rawahy, M., \& Habbal, O. (2012). Anatomy practical examinations: how does student performance compare. Anat Sci Educ, 5(1), 27-32. https://doi.org/10.1002/ase.254

Jack, A., \& Burbridge, B. (2012). Utilisation of Radiology for the Teaching of Anatomy in Canadian Medical Schools. Canadian Association of Radiologists Journal, 63(3), 160-164. https://doi.org/10.1016/j.carj.2010.11.005

Jarivapong, P., Punsawad C., Bunratsami S., and Kongthong P. (2016). Body painting to promote selfactive learning of hand anatomy for preclinical medical students. Med Educ Online, 21, 308- 333.

Kemeir, M. A. (2012). Attitudes and views of medical students toward anatomy learnt in the preclinical phase at King Khalid University. Journal of Family and Community Medicine, 19(3), 190-193. https://doi.org/10.4103/2230-8229.102320

Khan, A. N., Baig, S., \& Zain, S. (2014). Importance of Cadaveric Dissection in Learning Gross Anatomy. Pakistan Journal of Medicine and Dentistry, 3(4), 31-35. 
Kotsis, S. V., \& Chung, K. C. (2013). Application of See One, Do One, Teach One Concept in Surgical Training. Plast Reconstr Surg, 131(5), 1194-1201. https://doi.org/10.1097/PRS.0b013e318287a0b3

Kurt, E., Yurdakul, S. E., \& Atac, A. (2013). An Overview of the Technologies used for Anatomy Education in terms of Medical History. Social and Behavioral Sciences, 103, 109-115. https://doi.org/10.1016/j.sbspro.2013.10.314

McLachlan, J. C., \& Regan de Bere, S. (2004). How we teach anatomy without cadavers. Clin Teach, 1, 49-52. https://doi.org/10.1111/j.1743-498X.2004.00038.x

McMenamin, P. G., McLachlan, J., Wilson, A., McBride, J. M., Pickering, J., Evans, D. J. R., \& Winkleman, A. (2018). Do we really need cadavers anymore to learn anatomy in undergraduate medicine? Medical Teacher, 40, 1020-1029. https://doi.org/10.1080/0142159X.2018.1485884

Memon, I. (2018). Cadaver Dissection is Obsolete in Medical Training. A Misinterpreted Notion. Med Princ Pract, 27, 201-210. https://doi.org/10.1159/000488320

Mutalik, M., \& Belsare, S. (2016). Methods to learn human anatomy: perceptions of medical students in paraclinical and clinical phases regarding cadaveric dissection and other learning methods. International Journal of Research in Medical Sciences, 4(7), 2536-2554. https://doi.org/10.18203/2320-6012.ijrms20161888

Nnodim, J. O. (1990). Learning human anatomy: by dissection or from prosections? Medical Education, 24(4), 389- 395. https://doi.org/10.1111/j.1365-2923.1990.tb02456.x

Op Den Akker, J. W., Bohnen, A., Oudegeest, W. J., \& Hillen, B. (2002). Giving colour to a new curriculum: body paint as a tool in medical education. Clin Anat, 15(5), 356- 362. https://doi.org/10.1002/ca.10049

Papa, V., \& Vaccarezza, M. (2013). Review Article: Teaching Anatomy in the XXI Century: New Aspects and Pitfalls. The Scientific World Journal; Article ID 310348. https://doi.org/10.1155/2013/310348

Patten, D. (2007). What lies beneath: The in-living anatomy teaching. Clin Teach, 4, 10-14. https://doi.org/10.1111/j.1743-498X.2007.00136.x

Patten, D. (2015). Using ultrasound to teach anatomy in the undergraduate medical curriculum: an evaluation of the experience of tutors and medical students. Ultrasound, 23(1), 18-28. https://doi.org/10.1177/1742271X14542173

Purvi, M., Ksheersagar, D. D., \& Mishra, D. (2015). Attitude of first year medical students towards dissection. J Cont Med A Dent, 3(1), 45-49. https://doi.org/10.18049/jcmad/319

Rani, A., Chopra, J., Rani, A., Verma, R. K., \& Pankaj, A. K. (2016). Reflections of medical students on cadaveric dissection in present scenario. Int J Cur Res Rev, 8(24), 1-5.

Rehman, F. U., Khan, S. N., \& Yunus, S. M. (2012). Students, perceptions of computer assisted teaching and learning of anatomy - in a scenario where cadavers are lacking. Biomedical Research, 23(2), 215-218.

Riederer, B. M., \& Bueno-López, J. L. (2014). Anatomy, respect for the body and body donation - a guide for good practice. The Teaching of Anatomical Sciences, 18(4), 361-368.

Roberts, D. (2010). Vicarious learning: A review of the literature. Nurse Education in Practice, 10(1), 1316. https://doi.org/10.1016/j.nepr.2009.01.017

Romero-Reveron, R. (2017). Venezuelan surgeons view concerning teaching human anatomical dissection. Anat Cell Biol, 50, 12-16. https://doi.org/10.5115/acb.2017.50.1.12

Russell, F. M., Herbert, A., Ferre, R. M., Zakeri, B., Echeverria, V., Peterson, D., \& Wallach, P. (2021). Development and implementation of a point of care ultrasound curriculum at a multi-site institution. Ultrasound J, 13(9). https://doi.org/10.1186/s13089-021-00214-w

Sadler, T. J., Zhang, T., Taylor, H. L., \& Brassett, C. (2018). The role of radiology in anatomy teaching in UK medical schools: a national survey. Clin Radiol, 73(2), 185-190. https://doi.org/10.1016/j.crad.2017.08.008

Samarakoon, L. B., Vithoosan, S., Kokulan, M. M., Dissanayake, D. J., Dissanayake, A. V., \& Jayasekara, R. (2016). Do Prosected Cross Sections Improve Students Understanding of Spatial and Radiological Anatomy? Anatomy Research International, Article ID, 8984704. https://doi.org/10.1155/2016/8984704 
Selcuk, I., Tater, I., \& Huri, H. (2019). Cadaveric anatomy and dissection in surgical training. Turk J Obstet Gynecol, 16(1), 72-75. https://doi.org/10.4274/tjod.galenos.2018.15931

Sectra. (2019). Sectra Educational Portal. http://www.medinostic.com/wpcontent/uploads/2016/11/brochure_sectra_education_portal_and_table.pdf

Sing, R., \& Tubbs, R. S. (2015). Should a Highly Skilled Surgeon be an Advanced Anatomist first? A View Point. Basic Sciences in Medicine, 4(4), 53-57. https://doi.org/10.5923/j.medicine.20150404.01

Swamy, M., \& Searle, R. F. (2012). Anatomy teaching with portable ultrasound to medical students. BMC Education, 12, 99-103. https://doi.org/10.1186/1472-6920-12-99

Tibrewal, S. (2006). The Anatomical Knowledge of Surgical Trainees: The Trainer's View. Ann R Coll Surg Engl (Suppl), 88(7), 240-242. https://doi.org/10.1308/147363506X113857

Toltech. (2019). VH Dissector for Medical Education: Anatomy for your career. https://www.toltech.net/anatomy-software/solutions/vh-dissector-for-medical-education

Topp, K. S. (2004). Prosection vs. Dissection, the Debate Continues: Rebuttal to Granger. The Anatomical Record (Part B: New Anat), 281, 12-14. https://doi.org/10.1002/ar.b.20037

Tseng, W. T., \& Lin, Y. P. (2016). "Detached concern" of medical students in a cadaver dissection course: A phenomenological study. Anat Sci Educ, 9, 265-271. https://doi.org/10.1002/ase.1579

Turney, B. W. (2007). Anatomy in a modern medical curriculum. Ann R Coll Surg Engl, 89, 104-107. https://doi.org/10.1308/003588407X168244

U.S. National Library of Medicine (NIH) (2019). The Visible Human Project. https://www.nlm.nih.gov/research/visible/visible_human.html

Wearn, A., \& Vnuk, A. (2005). Medical students and peer physician examination: two case studies of strategies to improve safety and increase acceptance. FOHPE, 7, 88-98.

Williams, S. R., Thompson, K. L., Notebaert, A. J., \& Sinning, A. R. (2019). Prosection or Dissection: Which is best for Teaching Anatomy of the Hand and Foot? Anat Sci Educ, 12(2), 173-180. https://doi.org/10.1002/ase.1808.

Zurada, A., St. Gielecki, J., Osam, N., Tubbs, S., Loukas, M., Zurada-Zielinska, A., Bedi, N., \& Nowak, D. (2011). The study techniques of Asian, American, and European medical students during gross anatomy and neuroanatomy courses in Poland. Surg Radiol Anat, 33, 161-169. https://doi.org/10.1007/s00276-010-0721-6. 